\title{
Políticas de atenção primária e reformas sanitárias: discutindo a avaliação a partir da análise do Programa Saúde da Família em Florianópolis, Santa Catarina, Brasil, 1994-2000
}

\author{
Primary care policies and health reforms: \\ an evaluative approach based on an analysis \\ of the Family Health Program in Florianópolis, \\ Santa Catarina, Brazil, 1994-2000
}

Eleonor Minho Conill 1

1 Núcleo de Apoio à Municipalização $e$ Implementação do SUS, Departamento de Saúde Pública, Universidade Federal de Santa Catarina. Rua Vento Sul 306, Florianópolis, SC 88063-070, Brasil. eleonorc@bol.com.br

\begin{abstract}
This article discusses the evaluation of primary health care policies based on a case study of the Family Health Program in Florianópolis, Santa Catarina, Brazil. The results are presented in two stages. First, the Program is placed in the context of the Municipality's policies, identifying perceptions of the Program at the administrative level. Second, the author studied the Program's practices based on a sample of five family health care teams using an evaluative framework including variables on accessibility and comprehensiveness. The Program began relatively late in the State capital, but developed a unique model. There is a greater supply of services available to the population not covered by private health plans, although there is a major diversity of practices. The degree of implementation is moderately adequate: the care provided is more comprehensive, but there are problems with access (in the ratio between staff and number of families covered). It is suggested that such proposals for reorienting health care models tend towards rationalization, political legitimization, or democratization of services. The accessibility policy can set the predominant direction.
\end{abstract}

Key words Evaluation; Primary Health Care; Family Health Program; Health Policy

Resumo Discute-se a avaliação de políticas de atenção primária, a partir da análise do caso de implantação do Programa Saúde da Família (PSF) em Florianópolis, Santa Catarina, Brasil. Os resultados são apresentados em duas etapas. Na primeira, o programa foi contextualizado nas políticas municipais identificando-se sua percepção em nível de gestão. Na segunda, foram estudadas as práticas numa amostra de cinco equipes usando-se o acesso e a integralidade como categorias operativas. O PSF começa com relativo atraso na capital passando de principiante para um modelo singular. Há maior disponibilidade da oferta para a população não beneficiária de planos de saúde, embora haja ainda grande diversidade das práticas. O grau de implantação é moderadamente adequado: há maior integralidade na atenção, mas existem problemas no acesso (relação equipe/número de famílias). Sugere-se que tais propostas de reorientação de modelos assistenciais tendem à racionalização, legitimação política ou democratização dos serviços. $O$ encaminhamento da problemática referente ao acesso pode determinar a direção predominante. Palavras-chave Avaliação; Cuidados Primários de Saúde; Programa Saúde da Família; Política de Saúde 


\section{Introdução}

A reforma sanitária brasileira pode ser considerada tardia, preconizando princípios democráticos racionalizadores com implementação do Sistema Único de Saúde (SUS) numa conjuntura neoliberal. As mudanças ocorridas na política de saúde após a Constituição de 1988, teriam levado a uma inclusão segmentada, ou seja, diversos "cidadãos" de diferentes "qualidades" cobertos por distintos benefícios (Fleury, 1994). Apesar de avanços político-administrativos, reconhecem-se dificuldades para adequar o modelo assistencial aos princípios reformadores com maior eqüidade no acesso e na integralidade das práticas.

A descentralização, com a municipalização e a consolidação de sistemas locais segundo a estratégia da saúde da família, surgem como políticas setoriais que poderiam facilitar a superação dessas dificuldades (MS, 1993, 1994, 1996, 1998, 2001). Inicialmente considerado como um programa, o saúde da família é alçado à condição de estratégia para reorientação da assistência, que passaria a ser guiada pelos princípios de uma política de atenção primária ou de atenção básica.

Para alguns autores, estaria ocorrendo uma interação positiva entre este programa e a descentralização. O Programa Saúde da Família (PSF) teria favorecido a organização de Conselhos e Fundos e, ao evidenciar dificuldades no pagamento por procedimentos, teria contribuído para que as Normas Operacionais Básicas (NOBs) (MS, 1993, 1996, 2001) regulamentassem a remuneração das ações (Viana \& Dal Poz, 1998).

No entanto, torna-se necessário contextualizar para os países periféricos, o atual sentido e a efetividade dessas propostas de reordenamento do modelo assistencial, em função também de suas relações com idéias contidas no documento do Banco Mundial (1993) sugerindo uma ação estatal focalizada. Por essa razão, este texto traz elementos para a avaliação de políticas de atenção primária, tendo como referência sua emergência no país e o estudo do caso de sua implantação em Florianópolis, capital do Estado de Santa Catarina, no período 1994-2000.

Algumas hipóteses embasaram nosso estudo. A primeira delas é de que, embora alguns aspectos do conteúdo de reformas orientadas pela atenção primária sejam antigos, sua emergência como proposta organizativa para sistemas de saúde é mais recente e está ligada ao movimento de medicina comunitária americano dos anos 60 (Donnangelo \& Pereira, 1976).
Na trajetória de sua difusão surgiram diferentes denominações traduzindo reconstruções contextuais: atenção e cuidados primários, medicina simplificada, saúde ou medicina comunitária e no atual contexto brasileiro, saúde da família. A discussão acerca de continuidades e rupturas dessa formulação nacional, bem como a fundamentação dos fatores que explicariam tais reconstruções e o surgimento desta política em diferentes conjunturas, fogem dos objetivos deste trabalho mas podem, em parte, ser obtidas em estudos anteriores (Conill, 1982; Conill \& O'Neill, 1984). O que queremos salientar aqui é a presença constante dos seguintes princípios organizativos: territorialidade com adscrição de clientela, integralidade das ações, trabalho em equipe, apelo à participação e integração a um sistema regionalizado e hierarquizado.

A segunda hipótese é de que o conjunto desses princípios se articulariam em torno de dois pólos principais, um mais tecnocrático (medidas inovadoras e de racionalização das práticas) e outro mais participativo (democratização e controle social), sendo necessário investigar possíveis direções ou tendências a partir deles.

Quanto ao percurso realizado, começamos por selecionar estudos relacionados ao tema de forma a responder duas perguntas iniciais: quais as evidências e avaliações existentes quanto à viabilidade e resultados de políticas de atenção primária? Qual a situação da implantação dessa política no país? A primeira parte do texto apresenta uma síntese das respostas encontradas a estas questões.

Embora a avaliação implique num juízo de valor, a questão operacional continua predominante, fazendo com que seja a medida e não o juízo a questão mais desenvolvida. A omissão em tratá-la implica pôr em plano secundário a análise da situação inicial e da transformação pretendida, desconhecendo a existência de diversos olhares sobre uma mesma realidade e a necessidade de integrá-los. Optou-se então, por uma metodologia avaliativa abrangente para realização da parte empírica do trabalho, usando-se triangulação de método, fontes e dados, tendo escolhido o acesso e a integralidade enquanto categorias operativas, o que será melhor desenvolvido na parte referente à metodologia.

Na conclusão, estabelecemos um diálogo com os trabalhos selecionados, buscando aumentar a validade de nossos resultados, apontando aspectos referentes ao grau e tipo de implantação do programa em Florianópolis, além de sugerir que o acesso pode ser um possível indicador das tendências deste tipo de proposta no contexto brasileiro. 


\section{Efetividade da atenção primária, o SUS e a estratégia de saúde da família}

Em 1994, o PSF foi definido como "um modelo de assistência à saúde que vai desenvolver ações de promoção e proteção à saúde do indivíduo, da família e da comunidade, através de equipes de saúde, que farão o atendimento na unidade local de saúde e na comunidade, no nível de atenção primária" (MS, 1994:6). Além do atendimento, suas atividades incluem programação, grupos terapêuticos, visitas e internações domiciliares, entre outras.

Um novo manual (MS, 1998), enfatiza a reorientação da assistência e o caráter substitutivo do PSF que possibilitaria uma mudança das práticas centrada nos princípios da vigilância à saúde. Essa idéia do programa como modelo para o conjunto da rede consolida-se nos documentos mais recentes (MS, 2000, apud Bertoncini, 2000). Para o Ministério da Saúde (MS), seria um equívoco a idéia de que se trate de uma política para pobres com utilização de baixa tecnologia. A cobertura populacional prevista passa a ser de 600 à 1.000 famílias com limite máximo de 4.500 habitantes por equipe.

Dois trabalhos de envergadura nacional avaliaram o PSF. Vianna \& Dal Poz (1998), consideram-no uma estratégia de reforma incremental com expansão a partir de 1995/1996. Identificam três modelos: regional, singular e principiante. O que melhor dá resultados é o regional, fortemente apoiado por políticas estaduais sinérgicas (Ceará e Pernambuco). Há aumento da produção, o tipo de gestão não parece interferir, havendo problemas na composição e manutenção das equipes. As visitas a domicílio são realizadas principalmente pelos agentes, com pouco envolvimento dos profissionais de nível superior. O PSF teria se expandido num vazio programático para a questão assistencial do SUS, argumentando-se não existir conflito na focalização dentro do universalismo.

Outro trabalho importante foi um inquérito realizado com 3.119 equipes de 1.219 municípios de 24 estados, (80\% de participação em Santa Catarina) (MS, 2000). Os resultados nacionais mostraram que a implantação ocorreu entre 1997 e 1998, sendo a equipe mínima formada por médico, enfermeiro, auxiliar/técnico de enfermagem e agente comunitário de saúde (ACS) (dos outros profissionais citados, o odontólogo foi o principal com 28,8\%).

Há alto percentual de adesão aos princípios chaves tais como: definição do território, adscrição das famílias, cadastro, prontuário familiar e agenda. Foi referida a ampliação do acesso nas seguintes atividades: pré-natal, assis- tência à puérpera, criança, adolescente, adultos, idosos, pequenas cirurgias, coleta para exame papanicolau, planejamento familiar, consulta ginecológica, controle da hipertensão, diabetes, DST, hanseníase e tuberculose e vigilância epidemiológica (75\% das equipes). Afirmase haver disponibilidade relativamente boa de instrumentos e apoio diagnóstico básico em mais de $50 \%$ das equipes, já a cultura de urina, eletrocardiograma, colposcopia e ultra-sonografia existem em menos de $50 \%$. Somente $15 \%$ dispunham de todas as condições para a realização do pré-natal.

A maioria dos coordenadores estaduais e secretários municipais afirmou que o PSF vem se constituindo em uma estratégia de reorganização da atenção básica. As principais limitações para sua operacionalização seriam decorrentes da formação inadequada dos profissionais, número insuficiente de médicos, falta de recursos financeiros e de entendimento por parte dos gestores.

Bertoncini (2000) analisou a implantação do PSF em Blumenau, complementando a base desse inquérito com triangulação de dados e fontes. Há concordância quanto ao aumento do acesso e da integralidade, mas é provável que os porcentuais do aumento de atividades estejam super estimados. Utilizando a classificação de Merhy (1997, apud Bertoncini 2000), a autora mostrou que as tecnologias "leves" (vínculo, acolhimento) e "leve-duras" (saberes estruturados do processo de trabalho) não são pré-determinadas e variam entre as equipes. Em outro estudo neste mesmo município catarinense, o programa foi identificado por gestores, técnicos e conselheiros como um dos responsáveis por inovações e pelo resultado favorável encontrado entre a descentralização e melhorias no acesso e na integralidade do sistema municipal. Houve discreta diminuição das internações hospitalares no período (19941998), relacionada à efetividade da rede básica (Ortiga, 1999).

Alguns estudos enfocaram a avaliação da atenção primária e da saúde comunitária no âmbito internacional. A análise da implantação da reforma quebequense nos anos 70, mostrou que a integralidade da atenção ("la globalité") foi o objetivo com maior expressão prática nos Centros Locais de Serviços Comunitários (CLSC), porta de entrada da nova rede. No entanto, apesar de terem ocorrido inovações, tais práticas permaneceram marginais, não sendo suficientes para imprimir uma mudança no modelo assistencial (os médicos praticando nos CLSC representavam na época, em torno de $10 \%$ dos generalistas da província). Porém, 
essas organizações voltam à cena na reforma mais recente, em função da chamada "virada ambulatorial" (Conill, 1982, 2000; Godbout, 1979).

Vejamos agora mais alguns elementos acerca da implantação de uma política dessa ordem no contexto brasileiro, por meio da análise do caso do PSF em Florianópolis. Após algumas considerações metodológicas, apresentamos o resultado da avaliação realizada, dividindo-a em duas etapas: percepção do programa em nível de gestão e o perfil das práticas em nível local.

\section{Metodologia}

Num primeiro momento, o programa foi contextualizado nas políticas municipais, identificando-se sua percepção em nível de gestão (dezembro/1999 - março 2000) com análise temática a partir de entrevistas semi-estruturadas com técnicos e gestores, documentos, atos legislativos e observação participante da IV Conferência Municipal de Saúde. Na segunda, foram estudadas as práticas numa amostra intencional de cinco equipes por meio de observação direta, entrevistas, documentos e análise quantitativa do Sistema de Informação da Atenção Básica (SIAB). O universo compreendia as 25 equipes existentes no período 2000/2001. A amostra levou em conta, critérios que podem influenciar o produto de uma organização de atenção primária tais como, contexto ou características da comunidade, história e interesses dos atores que iniciam a experiência (Conill, 1982; Godbout \& Martin, 1974). A escolha foi discutida com informantes chaves para aumento da validade. Sua composição final representou o município em termos de região, tipo de comunidade e antigüidade das equipes. As letras $\mathrm{G}$ e $\mathrm{P}$ e os números 1 e 2, identificam gestores e profissionais da primeira e segunda gestões e a letra C, coordenador de equipe local, sem especificação do posto de saúde para preservação do anonimato.

Para fins exploratórios, incluiu-se no estudo a opinião de vinte famílias, quatro por equipe, solicitando-se ao agente que indicasse duas freqüentadoras e duas pouco freqüentadoras. $\mathrm{Na}$ amostra final predominaram as seguintes características: os respondentes foram mães, primeiro grau incompleto, renda familiar de 1 a 3 salários, compostas de 4 a 6 pessoas, acesso à água potável, tempo de moradia na área superior a dez anos.

A operacionalização das variáveis teve como referência os princípios do PSF, que deve- riam ter uma expressão na prática, articulados em torno de dois grandes blocos: o acesso e a integralidade. A escolha dessas categorias fundamentou-se em dar continuidade a estudos realizados nessa linha de pesquisa (Bertoncini, 2000; Hortale et al., 1999; Ortiga, 1999). Também foram consideradas como variáveis, os fatores explicativos ou condições relacionadas com os efeitos desse programa (estrutura ou condições para desempenho, contexto, história e características da equipe), já controlados no processo de amostragem. A grade avaliativa foi construída de forma concomitante à coleta e análise dos dados para verificação de sua viabilidade e validade, apresentando-se sua formulação final na Tabela 1.

Utilizaram-se três roteiros para coleta de dados (janeiro/maio de 2001): condições de estrutura, entrevista com coordenadores e famílias, relatórios do SIAB (08/2000-04/2001), complementados por diários de campo e outros documentos. O SIAB fornece dados do cadastramento das famílias, acompanhamento de grupos prioritários e marcadores de desempenho, além do registro de atividades. Por ter sido implantado recentemente, foi necessário estudo preliminar para seleção das informações com maior validade de conteúdo e preenchimento.

\section{O PSF no contexto das políticas municipais e a percepção em nível de gestão}

No inicio do século XX, ocorrem intervenções no meio com o saneamento e modernização urbana da capital catarinense. Nos anos trinta e quarenta, a estrutura sanitária é reorganizada por orientação do Departamento Nacional de Saúde, criando-se o Departamento Estadual de Saúde Pública. O Estado foi dividido em Distritos Sanitários, todos com um Centro de Saúde, sendo Florianópolis sede do primeiro desses distritos, com amplo Centro de Saúde localizado em área central. Em 1950, surgem hospitais estatais consolidando-se as Secretarias Estadual e Municipal. Esta última, apenas recentemente foi desmembrada da Secretaria de Educação (Lei 2.350/85).

A capital se modificará muito a partir dos anos 60 e 70, com a abertura da Universidade Federal, novos órgãos públicos e obras de infra-estrutura obedecendo a estratégia governamental de um projeto catarinense de desenvolvimento. No entanto, somente a partir de 1970 é que a Prefeitura começa a contratar médicos e os Postos vão surgindo no interior da ilha. 


\begin{tabular}{|c|c|c|}
\hline Variável/Dimensão & Indicadores & Medida \\
\hline \multicolumn{3}{|l|}{ Acesso } \\
\hline Físico & $\begin{array}{l}\text { Área, material, equipamentos, } \\
\text { recursos humanos }\end{array}$ & $\begin{array}{l}\text { Observação direta; relação } \\
\text { equipes/população cadastrada; }\end{array}$ \\
\hline Vínculo psico-sociocomunitário & $\begin{array}{l}\text { Disponibilidade de serviços } \\
\text { e interação }\end{array}$ & Observação, entrevistas; \\
\hline \multicolumn{3}{|l|}{ Integralidade } \\
\hline Caráter completo do cuidado & Gama de serviços ofertados & $\begin{array}{l}\text { Produção por prioridades } \\
\text { epidemiológicas/perfil da demanda; } \\
\text { ações curativas, preventivas e } \\
\text { promoção; situação dos marcadores; }\end{array}$ \\
\hline Continuidade & $\begin{array}{l}\text { Referência; acompanhamento } \\
\text { dos grupos de risco; atendimento } \\
\text { domiciliar }\end{array}$ & $\begin{array}{l}\text { Percepção; relação cadastrado/ } \\
\text { acompanhado; visitas/famílias; } \\
\text { distribuição para integrantes. }\end{array}$ \\
\hline
\end{tabular}

Fonte: Conill et al. (2001).

Cresce no cenário nacional, o movimento pela reforma sanitária e integração dos serviços. Há um convênio inovador de Ações Integradas no Município de Lages (1985), mas é a promulgação do SUS que desencadeará no estado um processo rápido e marcante de descentralização, com maior autonomia técnica e financeira decorrente do repasse da totalidade dos recursos para alguns municípios (Norma Operacional Básica 01/93). A Secretaria Municipal de Desenvolvimento Social (SMDS) de Florianópolis, no entanto, assume a modalidade de gestão parcial, incorporando sob sua gerência apenas os serviços de saúde de atenção básica da capital.

A população de Florianópolis é hoje da ordem de 280 mil habitantes. Embora haja diminuição no crescimento, a cidade vem recebendo fluxos migratórios com formação de bolsões de pobreza. As atividades econômicas são centradas no setor terciário. No perfil epidemiológico destaca-se a queda da mortalidade infantil a partir da década de 90, atualmente inferior à do estado. Além da mortalidade por doenças do aparelho circulatório e das causas externas, problemas comuns ao conjunto da sociedade brasileira, chamam a atenção localmente, as neoplasias, as doenças respiratórias e a AIDS. A rede pública municipal tem 51 unidades com 15 centros de saúde tipo II/CSII e 32 tipo I/CSI. Das equipes atuais de PSF 13 situam-se em CSI e 12 em CSII.

Em 1994, foi assinado o convênio para implantação de 28 equipes de saúde da família no
Estado de Santa Catarina. A capital mostra particularidades nesse sentido com atraso relativo em comparação a outros municípios de porte semelhante. As discussões iniciaram-se nesse ano, mas somente em 1996 foram implantadas seis equipes cobrindo quatro áreas, aumentando esse número para 25 no período de 1997 / 2000 , conforme veremos a seguir.

Diversas razões foram enumeradas para explicar esse atraso, mas o que prepondera é a questão político-ideológica, tanto no sentido de oposição ao seu conteúdo, como pela existência de projeto gerencial próprio da Frente Popular, coligação de centro-esquerda responsável pelo poder municipal nesta gestão. Foram priorizadas oficinas de territorialização para a rede como um todo, numa conjuntura nacional em que a proposta ainda não era considerada uma estratégia de reforma do modelo assistencial, sem segurança de sua continuidade.

É a troca de orientação política do poder municipal que determinará mudanças importantes nas características de sua implantação. Passa-se agora para uma fase expansionista com uma política denominada de "internação do PSF”, que significará adequar gradativamente todas as unidades da rede aos seus princípios. Outro aspecto desta nova etapa é a grande expansão do Programa de Agentes Comunitários de Saúde (PACS), pouco comum em capitais da Região Sul, com 561 agentes, sendo Florianópolis a primeira capital com cobertura total da população. Assim, chega-se ao número 
de 25 equipes com 20 áreas cobertas, igualdade numérica a das cidades pioneiras.

Há uma diferença na percepção do programa entre as duas gestões. Para a gestão que o inicia, apesar de sua expansão, o PSF abre caminho para o clientelismo, encerrando contradições importantes como a tensão entre "medicina para pobres" ou catalisador de mudanças na qualidade dos serviços, ou ainda um apelo para simples obtenção de recursos financeiros.

"Falta só a postura de assumir o PSF, podendo ter dois objetivos, realmente melhorar a tua assistência à saúde ou fazer uma política clientelista e assistencialista dentro dos moldes que eu já comentei, contratar o mínimo possível, botar para atender a população para amenizar a tensão social e captar isso na época das eleições..." (P1).

Para a gestão atual trata-se de uma política de reforma incremental que acrescenta à descentralização (MS, 1993, 1996, 2001), uma proposta de reorientação do modelo, com ênfase na promoção e prevenção favorecendo uma racionalização salutar ao setor, com diminuição de internações.

"Eu acho que foi uma das melhores idéias surgidas dentro do SUS, desde que surgiu o SUS, porque realmente, o PSF funcionando, ele resolve $90 \%$ dos problemas da população, não precisa internar, não precisa ir atrás de exame especializado, então é um investimento que se faz e lá na frente se está ganhando. É um investimento que, pegando o dinheiro de quem não é internado, que não faz exames, etc., dá para pagare sobra dinheiro, não tenho dúvida disso. Foi uma das melhores politicas que foram feitas $u l$ timamente. Ele funcionando diminui as emergências, as internações" (P2).

Ancorada nessa percepção positiva, essa gestão pretende adequar toda a rede aos princípios do programa, estratégia que é vista também, como uma forma de expandi-lo a menor custo: é oferecida para as equipes existentes a possibilidade de dobrar a carga horária complementando-se a diferença salarial. O cadastramento de toda a cidade com sua divisão em microáreas, a atuação dos agentes e a implantação do SIAB completariam o círculo da estratégia expansionista.

$\mathrm{O}$ atual perfil das práticas corresponde a três modalidades: modelo "clássico", equipes do Distrito Docente-Assistencial (DDA) (convênio com a Universidade Federal) e equipes do PSF, estas se diferenciando em etapa inicial e etapa de expansão. A problemática apontada pelos entrevistados na implantação do programa pode ser classificada em três grandes blocos: recursos humanos, financiamento e aspectos gerenciais e organizacionais. Há um grande consenso quanto ao fato de que os recursos humanos constituem problemática central. Recrutamento, capacitação, motivação, supervisão e rotatividade foram os principais problemas apontados. Obter pessoal com formação adequada, principalmente no que se refere aos médicos, esbarra no número reduzido de residências nessa área e na atração pelas especialidades com maior absorção no atual mercado de trabalho. Sendo os recursos escassos, a capacitação, a educação continuada e a supervisão aparecem como uma fragilidade na implantação do modelo expandido na rede. A esse fato somam-se dificuldades pelas demandas psico-afetivas e de ordem ética, que implicam a prática coerente com as propostas de saúde da família. Outro bloco importante de questões, refere-se a aspectos gerenciais e organizacionais: composição e tamanho da equipe, referência para especialidades e apoio diagnóstico, compatibilização com programas existentes, relação PACS/PSF, acompanhamento, controle e avaliação, e apoio estadual. Apontase a necessidade de diminuir o número de famílias a serem cuidadas, além de realizar uma adequação de sua composição de forma a incluir outros profissionais.

A relação entre PACS e PSF gera controvérsias, determinadas pelo grande número de agentes e por seu treinamento orientado para a função de auxiliar de enfermagem. Para um grupo de entrevistados isto os desviaria da função comunitária e de vigilância, dirigindo-os para cuidados, além de contemplar objetivos clientelísticos. Para outros, traz a garantia de que as famílias serão melhor acompanhadas. O fato de estarem rastreando problemas prioritários pode inicialmente sobrecarregar a demanda com maior afluxo aos postos, mas seria também uma pressão para o aumento do número de equipes. No momento, esses dois programas não atuam de forma integrada. Há uma unanimidade de que a referência por serviços especializados e para apoio diagnóstico constitui um nó crítico.

A gerência, o acompanhamento, o controle e a avaliação do programa parecem ser ainda precários. Faltariam quadros técnicos mas a implantação do SIAB é vista com otimismo. Para uns, trata-se apenas de uma questão de tempo e ajuste; para outros, a estratégia expansionista se é positiva por difundir na rede os princípios de integralidade, quando não associada a um acompanhamento, traz o perigo de melhorias salariais sem diferenciação de desempenho.

Perguntados sobre os avanços do programa, os entrevistados referem: melhorias no acesso 
para população não beneficiária de planos de saúde, na prevenção com diminuição de internações, nos salários, nas formas de financiamento federal e, uma "contaminação" positiva do aparelho formador e do sistema de saúde. No entanto, a percepção de tais avanços não parece ser ainda generalizada. $\mathrm{Na}$ análise do material oriundo da observação participante da IV Conferência Municipal (2000), as proposições referentes ao PSF foram no sentido de sua ampliação, adequação das equipes e integração entre PACS e PSF, obtenção de melhorias no acesso e integralidade da rede. Isto significa que os resultados positivos do programa ainda não produziram efeitos visíveis para o público presente ao evento.

No entanto, o PSF evolui de um programa isolado para uma estratégia de reorientação do modelo assistencial na rede pública, havendo concordância quanto à visibilidade dessa trajetória tanto em nível local como nacional. Encerra no entanto contradições, tanto ideológicas quanto operacionais. Vejamos a prática.

\section{O perfil das práticas: acesso, integralidade e grau de implantação}

O posto Esperança trabalha com uma população mista, numa área onde convivem prédios de luxo com casas simples ou mesmo população desfavorecida. O perfil de utilização corresponde ao desse último grupo. Há um grande número de famílias por equipe. A estrutura física é excelente. Há uma ampla gama de serviços, incluindo prevenção, estando as visitas concentradas nos agentes. Houve capacitação variada para os diferentes componentes da equipe. É um posto próximo à área de gestão e por isso recebe boa supervisão. São apontados problemas de referência e seu desempenho nos dados quantitativos não corresponde, surpreendentemente, à média das equipes. Para a comunidade, o PSF significa os agentes. Embora o posto tenha facilidades de estrutura, o acesso, incluindo sua dimensão psicossocial, é referido como problemático.

Bem-Estar é um posto com características particulares pois faz parte do DDA. A comunidade é mista, no entanto, a diferença entre classes não é tão marcante quanto em Esperança. O que chama a atenção em Bem-Estar é a incorporação de atividades inovadoras, como uma farmácia viva e a grande referência à humanização dos cuidados e da postura do médico ali existente. Há uma boa estrutura mas são apontados problemas de sobrecarga no dimensionamento da equipe. A comunidade parece estar satisfeita com a humanização que encontra nesse posto.

A comunidade onde se situa o posto Primavera é antiga na ilha, de nível socioeconômico misto. Os dados da análise da demanda são coincidentes com suas características, revelando uma concentração da população adulta e coerência das atividades com essa demanda. Chama a atenção o alto porcentual de referência para atendimento especializado. $\mathrm{O}$ agente comunitário é de novo considerado como a principal mudança. Embora haja aumento da oferta de profissional médico, a inadequação da relação população/demanda é também o grande problema da equipe.

Já Vento Sul, ao contrário dos demais, tem condições de estrutura regular, sendo o único recurso de uma comunidade carente. $\mathrm{O}$ atendimento cobre o conjunto de faixas etárias. Relata-se uma interação importante com a comunidade, notando-se que na falta de motorista, foi o Conselho Comunitário que passou a exercer tais funções. A gama de serviços é ampla, mas os problemas também se concentram no dimensionamento da equipe e na referência. Para a comunidade e para a coordenação, o agente comunitário é quem faz a diferença; há visitas e uma oferta melhor de serviços inclusive preventivos (grupos de hipertensos e diabéticos). Mas citam-se os problemas de acesso já referidos.

Tradição é um posto antigo como Vento Sul, um dos primeiros na implantação do programa. A comunidade é pobre, com presença de movimentos sociais. No perfil de utilização predominam mães e crianças, o clássico de uma área desfavorecida. Há equipamentos e capacitação. A estrutura também não é adequada, seu problema é como nos demais, um quantitativo mal dimensionado. As atividades são coerentes com a clientela, aparecendo o PACS como o avanço mais expressivo, referido tanto pela coordenação como pela comunidade. A percepção da comunidade é coincidente com os problemas estruturais e de acesso, embora identifique uma diferença após a existência do PSF referindo melhorias na oferta.

Na análise comparada do perfil de utilização dos postos, nota-se um predomínio da faixa de 0-4 anos e de adultos jovens de 20-39. Em alguns postos já é evidente o envelhecimento da população usuária. A média de consultas é mais ou menos homogênea, da ordem de 700/ mês, com exceção conforme assinalado, do posto Esperança. A distribuição pelos principais tipos de atividades epidemiologicamente prioritárias mostra preponderância da puericultura e do pré-natal. Há adequação nos pos- 
tos Primavera e Vento Sul ao perfil de utilização, com porcentual expressivo de doenças crônico-degenerativas (hipertensão e diabetes). Isto não ocorre em Bem-Estar. Observa-se um alto porcentual de encaminhamentos no posto Primavera, os demais se situam em torno de $2-4 \%$ (Tabela 2).

A relação equipe/famílias cadastradas é superior ao previsto em todos os postos, principalmente em Esperança (3.771 famílias) e Vento Sul (2.104). As visitas são feitas principalmente pelos agentes, os médicos realizam mais essa atividade do que a enfermagem, com exceção de Tradição e Esperança (Tabela 3). Os marcadores de processo e resultado mostram acompanhamento adequado de diabéticos, hipertensos e gestantes e crianças, situando-se acima de $80 \%$ dos cadastrados em todas as equipe.

A integralidade é entendida pelas coordenações dos postos como um conjunto amplo de ações, um acompanhamento diferenciado e ampliado de indivíduos, não apenas consulta. A percepção é de que o PSF gerou avanços na prevenção, na consciência sanitária e na realização de visitas domiciliares. $\mathrm{O}$ agente é citado como um grande fator de mudança nesse sentido. Há também uma maior disponibilidade de consultas médicas.

"Não melhorou só na questão de saúde, melhorou na questão de organização comunitária, de liderança, nós temos o Conselho Local de Saúde, que iniciou em 1996, foi o primeiro Conselho Local de Saúde que existe de Florianópolis, foi o nosso. Muita coisa melhorou, mesmo com todo esse problema que a gente vive hoje nós tivemos muito avanço dos serviços oferecidos aqui dentro" (C).

"O PSF está estimulando as pessoas a irem mais ao posto por causa dos agentes comunitários, os agentes comunitários vão na casa e sensibilizam as pessoas para que elas façam o seu acompanhamento de hipertensão, diabetes ou da criança. Ele vai lá busca, vê porque a criança faltou, ele mesmo agenda a consulta, traz aqui para mim ou quem está responsabilizado e coloca, agenda a consulta. Então a gente tem essa troca, a gente consegue fazer essa troca através do agente comunitário... Quando eu entrei aqui estava recém começando o PSF, não tinha tanto movimento quanto tem agora. Agora a gente tem uma demanda muito maior eu acho que esta troca está funcionando, a gente está conseguindo acompanhar as pessoas" (C).

A grande unanimidade, no entanto, é de que esses avanços são prejudicados pelo dimensionamento inadequado entre equipe e população. Cita-se que com isso, o tempo torna-se um impedimento à realização do menos comple- xo. Havendo problemas na referência para especialidades, o mais complexo torna-se também difícil. Estes fatos podem comprometer os avanços na integralidade.

"Ele poderia favorecer se tivesse equipe que coincidisse realmente com o que o Ministério preconiza, seria de 800 a 1.000 famílias. Mas quando tu tens duas equipes para atender quase o que 4 equipes fariam, tu não consegues nunca atender nem a questão do acesso nem nenhum dos princípios, acho, do SUS, se tu não tiver o número de equipe para atender" (C).

"A gente precisa da consulta com especialista para continuar acompanhando o paciente $e$ muitas vezes não se está conseguindo, então acho que isso afeta bastante a integralidade. Então acho que está sendo prejudicada não só no sentido do mais complexo, mas no sentido do menos complexo. Hoje eu não posso dar uma atenção menos complexa por que eu não tenho tempo, e eu não posso dar uma atenção mais complexa por que não tenho a referência funcionando"(C).

São citados como conseqüências desse mau dimensionamento, dificuldades para realização de visitas, grupos e seguimento de pacientes com curativos domiciliares, por exemplo. De um modo geral, a estrutura, a área física, seu estado de conservação e os equipamentos são considerados adequados para o exercício da atenção primária.

As dificuldades apontadas pela coordenação quanto ao acesso, coincidem com a percepção das famílias em obterem consultas no posto ou com especialistas. Consideram que há avanços, mas não conhecem o PSF como tal. A grande diferença é a existência do agente, embora refiram também as visitas e as atividades de grupos. Tanto população e coordenação, quando perguntadas a respeito do que mudariam, confirmam as dificuldades do acesso, pois as ações se concentrariam na contratação de profissionais e mudanças na estrutura física com maior oferta de serviços. As famílias citam ainda a necessidade de uma gama mais ampliada de atenção, referindo-se à figura do dentista.

O conjunto das informações obtidas gerou grades avaliativas do grau de implantação em cada uma das equipes. A síntese dos fatores explicativos/condições de implantação mostra que o PSF em Florianópolis está adequado no que se refere à sua estrutura física, área e equipamentos. É inadequado quanto ao item recursos humanos medido pela relação número de equipes/famílias, o qual está subdimensionado e, moderadamente adequado quanto à sua capacitação. No que se refere à gestão, o grau de implantação é moderado com maior 
Descrição das atividades de produção das equipes do Programa Saúde da Família.

Florianópolis, Santa Catarina, Brasil, agosto de 2000 a abril de 2001.

\begin{tabular}{|c|c|c|c|c|c|}
\hline & $\begin{array}{c}\text { Posto } \\
\text { Esperança }\end{array}$ & $\begin{array}{l}\text { Posto } \\
\text { Tradição }\end{array}$ & $\begin{array}{c}\text { Posto } \\
\text { Bem-Estar }\end{array}$ & $\begin{array}{c}\text { Posto } \\
\text { Primavera }\end{array}$ & $\begin{array}{c}\text { Posto } \\
\text { Vento Sul }\end{array}$ \\
\hline \multicolumn{6}{|l|}{ Consulta por faixa etária (\%) } \\
\hline$<1$ ano & 24,0 & 17,0 & 20,0 & 9,0 & 14,0 \\
\hline $1-4$ anos & 13,0 & 21,0 & 17,0 & 12,0 & 14,0 \\
\hline $5-9$ anos & 7,0 & 8,0 & 6,0 & 8,0 & 9,0 \\
\hline 10-14 anos & 2,0 & 5,0 & 4,0 & 7,5 & 6,0 \\
\hline $15-19$ anos & 7,0 & 8,0 & 7,0 & 5,5 & 8,0 \\
\hline 20-39 anos & 26,0 & 19,0 & 22,0 & 17,5 & 19,0 \\
\hline 40-49 anos & 6,0 & 8,0 & 6,0 & 13,5 & 7,0 \\
\hline $50-59$ anos & 6,0 & 7,0 & 5,0 & 15,0 & 7,0 \\
\hline 60 anos ou + & 9,0 & 8,0 & 13,0 & 11,5 & 15,0 \\
\hline Média mensal de consultas/equipe & 276 & 731 & 599 & 693 & 686 \\
\hline \multicolumn{6}{|l|}{ Tipo de atendimento $(\%$ - mensal) } \\
\hline Puericultura & 25,0 & 9,0 & 19,0 & 11,0 & 8,0 \\
\hline Pré-natal & 12,0 & 8,0 & 3,0 & 6,0 & 6,0 \\
\hline Preventivo cérvico-uterino & 4,0 & 4,0 & 5,0 & 5,0 & 4,0 \\
\hline Diabetes & 5,0 & 5,0 & 1,0 & 6,0 & 6,0 \\
\hline Hipertensão arterial & 5,0 & 9,0 & 1,0 & 14,0 & 9,0 \\
\hline \multicolumn{6}{|l|}{ Encaminhamentos (\%) } \\
\hline Atendimento especializado & 5,0 & 3,0 & 3,0 & 34,0 & 4,0 \\
\hline Internação hospitalar & 0,1 & 0,1 & 0,1 & - & 0,3 \\
\hline Urgência/emergência & 0,3 & 0,3 & 0,4 & 1,0 & 3,0 \\
\hline
\end{tabular}

Fonte: Conill et al. (2001).

Descrição das atividades de produção das equipes do Programa Saúde da Família - visitas domiciliares, médias mensais e por família. Florianópolis, Santa Catarina, Brasil, agosto de 2000 a abril de 2001.

\begin{tabular}{|c|c|c|c|c|c|}
\hline Posto & $\begin{array}{c}\text { Posto } \\
\text { Esperança }\end{array}$ & $\begin{array}{l}\text { Posto } \\
\text { Tradição }\end{array}$ & $\begin{array}{c}\text { Posto } \\
\text { Bem-Estar }\end{array}$ & $\begin{array}{c}\text { Posto } \\
\text { Primavera }\end{array}$ & $\begin{array}{c}\text { Posto } \\
\text { Vento Sul }\end{array}$ \\
\hline Médico & 1 & 11 & 6 & 11 & 14 \\
\hline Enfermeiro & 7 & 67 & 3 & 4 & 5 \\
\hline Outros profissionais de nível superior & 1,5 & - & 8 & - & - \\
\hline Profissional de nível médio & - & - & 3 & - & 3 \\
\hline Agente comunitário de saúde & 806 & 1.823 & 385 & $1.203,5$ & 1.878 \\
\hline Total de visitas & 815,5 & 1.901 & 405 & 1.218 & 1.900 \\
\hline Total de famílias cadastradas & 3.772 & 1.454 & 1.861 & 1.466 & 2.105 \\
\hline Média de visitas por família & 0,2 & 1,3 & 0,2 & 0,8 & 0,9 \\
\hline
\end{tabular}

Fonte: Conill et al. (2001). 
predomínio de desempenho inadequado no preenchimento e utilização do SIAB. Com isso, os efeitos no acesso apresentam-se adequados na dimensão física (área, material e equipamentos) e inadequados nos recursos humanos. $O$ vínculo psico sociocomunitário mostra-se de moderado a adequado.

$\mathrm{Na}$ integralidade, o caráter completo do cuidado se encontra adequado, com realização de atividades preventivas e curativas. A referência varia de inadequada a moderadamente adequada, sendo o cuidado domiciliar moderado em todas as equipes e o acompanhamento dos grupos prioritários de moderado a adequado. Esse resultado final é apresentado na Tabela 4.

\section{Conclusão: racionalização, legitimação do poder local ou democratização das práticas? Sobre a importância das relações entre o acesso e a integralidade para o sentido do PSF e de políticas de atenção primária}

A capital do estado mostra particularidades no processo de implantação do PSF com um atraso relativo em comparação a outros municípios de porte semelhante. No âmbito nacional esse atraso não é notório, uma vez que $83 \%$ dos municípios implantaram o programa entre 1997

Tabela 4

Grade avaliativa da implantação do Programa Saúde da Família.

Florianópolis, Santa Catarina, Brasil.

\begin{tabular}{|c|c|c|c|}
\hline & Inadequada & Moderada & Adequada \\
\hline \multicolumn{4}{|l|}{ Acesso } \\
\hline \multicolumn{4}{|l|}{ Físico } \\
\hline Área/material/equipamento & * & * & $\star \star \star$ \\
\hline \multicolumn{4}{|l|}{ Vínculo psico-sociocomunitário } \\
\hline Recursos humanos & $\star \star \star \star \star ~$ & $\star \star$ & $\star \star \star$ \\
\hline \multicolumn{4}{|l|}{ Integralidade } \\
\hline \multicolumn{4}{|l|}{ Caráter completo } \\
\hline Curativo & & & 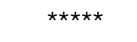 \\
\hline Preventivo & & & 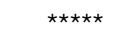 \\
\hline \multicolumn{4}{|l|}{ Continuidade } \\
\hline Referência & $\star \star$ & $\star \star \star$ & \\
\hline Atendimento domiciliar & & 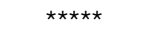 & \\
\hline Acompanhamento/prioridades & & $\star \star$ & $\star \star \star$ \\
\hline
\end{tabular}

Fonte: Conill et al. (2001). e 1998, evidenciando o quanto ele é recente (MS, 1999).

A análise da trajetória da implantação mostra, segundo tipologia de Viana \& Dal Poz (1998), a passagem de um modelo principiante para um modelo singular, caracterizado por rápida expansão com proposta de extensão ao conjunto da rede, presença maciça do PACS e existência de um DDA. A mudança da orientação política da gestão municipal não modificou apenas o ritmo e o estilo da implantação do programa diferindo também quanto ao seu significado.

Independente da gestão, há concordância de que os recursos humanos constituem problemática central, o que coincide com estudos anteriores (MS, 1999; Viana \& Dal Poz, 1998). Na percepção dos entrevistados, apesar das contradições, ocorreram avanços, mas sua visibilidade ainda não é amplamente perceptível. Apesar da intenção de estender os princípios do PSF para o conjunto das unidades, pelo menos quatro grandes perfis de prática existem hoje na rede pública: modelo clássico; DDA e PSF, dividido em equipes antigas e recentes. Há uma tendência de que práticas antigas persistam, mesmo nas equipes em transição, justificadas pela sobrecarga, mas também relacionadas com a cultura institucional e formação profissional.

A performance do programa é razoável em relação aos itens avaliados. Não encontramos relação com as condições de área física, equipamentos e materiais, e os efeitos na dimensão psico-sociocomunitária do acesso e na integralidade. Parecem ter maior influência nesse sentido, o tempo de implantação, o tipo de movimento social existente na comunidade e as características dos profissionais. Esse aspecto foi assinalado por Bertoncini (2000), em Blumenau, onde algumas equipes, embora sem condições, cumpriam os objetivos de integralidade do programa com incorporação de práticas inovadoras. O programa está adequadamente implantado nas dimensões físicas do acesso referentes à área, equipamentos e medicamentos, mas inadequado quanto aos recursos humanos, medidos pelo número de equipes/famílias. Ainda que se retire o porcentual da população não usuária do SUS essa relação permanece muito superior ao preconizado.

Há coincidência dos resultados com aqueles encontrados no inquérito nacional quanto às condições de estrutura (MS, 2000), e quanto à incorporação de práticas preventivas e de promoção com efeito positivo na integralidade, encontrado neste e em outros trabalhos (Conill, 1982; Godbout, 1979). 
A avaliação do nível local é coincidente com a percepção da gestão de que o PSF amplia o acesso da população a práticas mais integrais, no entanto, há uma diferença nesta percepção. É muito maior a ênfase do nível local na problemática decorrente do mau dimensionamento das equipes e das dificuldades na referência. Quanto ao caráter completo do cuidado, tanto comunidade como coordenação local consideram importante ampliar o leque das ações e de programas, evitando-se monopólio daqueles prioritários em nível central.

A grande visibilidade do PSF se dá pela presença maciça dos ACS, responsáveis pelas visitas e acompanhamento dos grupos prioritários. Os agentes e o PACS são responsáveis em grande parte, pelos efeitos positivos na integralidade em função das visitas e acompanhamento desses grupos, o que introduziu um viés importante que deve ser considerado.

Os problemas no acesso, decorrentes do quantitativo insuficiente de recursos humanos e as dificuldades na referência, determinam uma situação que este estudo identifica como das mais relevantes. A barreira do acesso pode vir a dificultar as vantagens obtidas nos demais itens da integralidade, impedindo a realização do menos complexo por falta de tempo (prevenção, visitas). Havendo problemas na referência para especialidades, o mais complexo toma-se também difícil e a qualidade prejudicada. Ou ao contrário, como citado por alguns integrantes da gestão, isto pode vir a constituir-se num mecanismo de pressão para ajuste: os agentes ao identificarem problemas, mo- bilizam a comunidade gerando um contexto favorável para que se ampliem os recursos.

O encaminhamento desta questão dependerá da capacidade de gestão aliada à conjuntura nacional, principalmente no que se refere ao financiamento das políticas públicas, de forma a permitir a ampliação do programa consolidando os avanços obtidos. Dos caminhos traçados na resolução desta contradição dependerá a dinâmica dos eixos principais, em torno dos quais parece se articular esse tipo de proposta de reorganização de serviços de saúde: racionalização da atenção para populações mais ou menos excluídas do processo de produção, legitimação política ou democratização, com qualidade nas práticas e no acesso.

Foi possível verificar que o PSF de fato, evolui de um programa isolado para uma estratégia de reorientação do modelo assistencial na rede pública, havendo concordância quanto à visibilidade de sua trajetória e efeitos positivos na integralidade. Acumulam-se evidências apontando para a viabilidade de práticas mais abrangentes, alternativas ao modelo biomédico tradicional. Já havia sido demonstrada na reforma de Quebec, a possibilidade de que as organizações incorporem inovações no sentido de uma maior integralidade das ações de atenção primária. Tais práticas permaneceram marginais, não sendo suficientes para imprimir uma mudança no modelo assistencial. A manutenção e difusão do PSF, parecem indicar uma maior potencialidade nesse sentido dentro do sistema público na reforma brasileira, ainda que cercada de um conjunto de contradições.

\section{Agradecimentos}

Esta pesquisa contou com recursos parciais do Programa Institucional de Bolsas de Iniciação Científica (PIBIC)/Conselho Nacional de Desenvolvimento Científico e Tecnológico (CNPq). A autora agradece a Giovana Bacillieri Soares e Fernanda Freitas, acadêmicas de Medicina da Universidade Federal de Santa Catarina (UFSC), pela participação na coleta de dados e aos profissionais e chefias da Secretaria Municipal por sua disponibilidade. 


\section{Referências}

BANCO MUNDIAL, 1993. Relatório sobre o Desenvolvimento Mundial 1993: Investindo em Saúde. Washington, D.C.: Banco Mundial.

BERTONCINI, J. H., 2000. Da Intenção ao Gesto - Análise da Implementação do Programa de Saúde da Família em Blumenau. Dissertação de Mestrado, Florianópolis: Departamento de Saúde Pública, Universidade Federal de Santa Catarina.

CONILL, E. M., 1982. Les Implications de la Santé Communautaire en tant que Nouvelle Politique de Santé. Analyse du Cas du Québec. Thèse de Doctorat, Paris: Institut du Développement Economique et Social, Sorbonne.

CONILL, E. M., 2000. A recente reforma dos serviços de saúde na província do Québec, Canadá: As fronteiras da preservação de um sistema público. Cadernos de Saúde Pública, 16:963-971.

CONILL, E. M. \& O’NEILL, M., 1984. La notion santé communautaire: Eléments de comparaison internationale. Canadian Journal of Public Health, 75:166-175.

CONILL, E. M.; SOARES, G. B. \& FREITAS, F. L., 2001. Análise da implantação do Programa de Saúde da Família no Município de Florianópolis, Santa Catarina - 1994/2001: O Perfil das Práticas. Relatório de Pesquisa. Florianópolis: Departamento de Saúde Pública, Universidade Federal de Santa Catarina.

DONNANGELO, F. M. C. \& PEREIRA, L., 1976. Saúde e Sociedade. São Paulo: Duas Cidades.

FLEURY, S., 1994. Estado sem Cidadãos - Seguridade Social na América Latina. Rio de Janeiro: Editora Fiocruz.

GODBOUT, J., 1979. La distribution du pouvoir et les changements suscités par les CLSC. In: La Décentralisation en Pratique, Quelques Expériences Montréalaises, 1970-1977 (G. Divay, ed.), pp. 169238, Montréal: Institut National de Ia Recherche Scientifique.
GODBOUT, J. \& MARTIN, N., 1974. Participation et Innovation: L'Implantation de CLSC et les Organismes Communautaires Autonomes. Montréal: Université du Quebéc.

HORTALE, V.; CONILL, E. M. \& PEDROZA, M., 1999. Desafios na construção de um método para análise comparada da organização de serviços de saúde. Cadernos de Saúde Pública, 15:79-88.

MS (Ministério da Saúde), 1993. Norma Operacional Básica do Sistema Único de Saúde/NOB-SUS 93. Gestão Plena com Responsabilidade pela Saúde do Cidadão. Brasília: MS.

MS (Ministério da Saúde), 1994. Saúde da Família: Uma Estratégia para a Reorientação do Modelo Assistencial. Brasília: MS.

MS (Ministério da Saúde), 1996. Portaria no 2.203 de 1996. Dispõe sobre a Norma Operacional Básica do SUS 01/96. Brasília: MS.

MS (Ministério da Saúde), 1998. Programa de Saúde da Família - Saúde Dentro de Casa. Brasília: Fundação Nacional de Saúde, MS.

MS (Ministério da Saúde), 2000. Avaliação da Implantação e Funcionamento do Programa de Saúde da Família. Brasília: Coordenação da Atenção Básica, Secretaria de Assistência à Saúde, MS.

MS (Ministério da Saúde), 2001. Portaria no 95 de 26 de janeiro de 2001. Dispõe sobre a NOAS Norma Operacional da Assistência à Saúde. Brasília: MS.

ORTIGA, A. M. B., 1999. Efeitos da Municipalização no Acesso e na Integralidade dos Serviços de Saúde, Blumenau, SC, 1994-1998. Dissertação de Mestrado, Florianópolis: Departamento de Saúde Pública, Universidade Federal de Santa Catarina.

VIANA, A. L. D. \& DAL POZ, M. R., 1998. A reforma sanitária do sistema de saúde no Brasil e Programa de Saúde da Família. Physis - Revista de Saúde Coletiva, 8:12-48.

Recebido em 5 de outubro de 2002 Aprovado em 16 de outubro de 2002 